\title{
PROPOSTA DE IMPLEMENTAÇÃO DA FERRAMENTA CRM NO RELACIONAMENTO COM CLIENTES E COLABORADORES: ESTUDO DE CASO NA EMPRESA VAP INFORMÁTICA LTDA
}

\section{ARTIGO ORIGINAL}

SILVA, Matheus Dantas da ${ }^{1}$, SILVA JUNIOR, Paulo Egídio Ribeiro da ${ }^{2}$, MACIEL, Pedro Henrique Pereira ${ }^{3}$, RAMOS, Jose Manoel ${ }^{4}$, ROBERTO, Jose Carlos Alves ${ }^{5}$

SILVA, Matheus Dantas da. Et al. Proposta de implementação da ferramenta CRM no relacionamento com clientes e colaboradores: estudo de caso na empresa Vap Informática LTDA. Revista Científica Multidisciplinar Núcleo do Conhecimento. Ano 06, Ed. 05, Vol. 09, pp. 122-149. Maio de 2021. ISSN: 24480959, Link de acesso: https://www.nucleodoconhecimento.com.br/marketing/ferramenta-crm, DOI: 10.32749/nucleodoconhecimento.com.br/marketing/ferramenta-crm

\section{RESUMO}

O presente estudo realizado na empresa VAP INFORMÁTICA evidenciou-se a partir da análise problemática e possível proposta de solução necessária para mudanças

\footnotetext{
1 Graduação em administração.

2 Graduação em Administração.

3 Graduação em Administração.

${ }^{4}$ Coorientador. Especialista MBA, docente em pós-graduação e graduação gestão e negócios.

${ }^{5}$ Orientador. Mestrado profissional em Engenharia de produção. Especialização em Gestão em Logística empresarial. Graduação em Administração com Ênfase em Marketing.
}

$\mathrm{RC}: 85362$

Disponível em: https://www.nucleodoconhecimento.com.br/marketing/ferramenta-crm 
positivas dentro da empresa, identificou-se através de entrevistas e questionários dentro da área do Marketing como sendo a de menor desempenho. Aprofundou-se o estudo delineado como objetivo geral reter, aprofundar e captar novos e fiéis clientes a partir da gestão do marketing de serviços na empresa. Sendo assim, o objetivo do projeto foi criar uma proposta de implementação futura para a empresa VAP INFORMATICA, identificando com a aplicação da ferramenta CRM para melhoria contínua e o mapeamento dos processos da empresa, como objetivos específicos buscou-se identificar quais as dificuldades que podem ser encontradas durante a etapa de implementação da ferramenta CRM; Especificar as principais vantagens proporcionadas na utilização da Ferramenta CRM para o encantamento, captação e retenção de novos clientes; Analisar as estratégias e identificar porque o CRM é importante para os colaboradores da empresa em nível de continuidade dos atendimentos com a clientela.

Palavras-Chave: CRM, Implantação, Empresa, Clientes, Relacionamento.

\section{INTRODUÇÃO}

No passado, não havia muita atenção em deixar os clientes totalmente satisfeitos, porque a competição entre produtos é diferente, a qualidade das empresas concorrentes costuma ser semelhante, claro, a situação mudou.

Em um mercado altamente competitivo, é preciso não só enfatizar as vendas, mas também desenvolver relacionamentos.

$\mathrm{Na}$ era industrial, a maior preocupação da empresa é comprar o máximo de máquinas possível para produzir produção em massa, à medida em que os produtos são vendidos, mais capital é gerado e mais máquinas são compradas, portanto, o recurso básico é o capital. Atualmente, os requisitos de competitividade estão

$\mathrm{RC}: 85362$

Disponível em: https://www.nucleodoconhecimento.com.br/marketing/ferramenta-crm 
relacionados à capacidade de integração de toda a empresa e à capacidade de atender às suas particularidades.

Então, o recurso básico é a informação, como a informação é o recurso mais importante hoje, deve haver um grande número de fontes de informação.

Desta forma, a chamada tecnologia da informação (TI) tem passado por um amplo período de expansão por meio da utilização de equipamentos, serviços prestados ao público e informações fornecidas por softwares cada vez mais complexos.

Essa demanda ampliada é uma questão de sobrevivência, pois se está em um ambiente extremamente competitivo e é quase impossível competir, para se conseguir a integração dos processos, é necessário buscar diretrizes na gestão da empresa gerenciar melhor processos, informações, recursos e pessoas.

Para promover a adoção de estratégias de gestão nas organizações, algumas ideias desempenham um papel norteador na utilização de conceitos e na construção de estratégias de gestão.

No passado recente, as organizações empresariais compreendiam facilmente os seus clientes devido ao pequeno número de clientes, e ao seu estilo de vida na organização empresarial, para que possam servir separadamente.

Desta forma, o proprietário mantém a gestão da propriedade, mas com o aumento da demanda, é necessário atender aos requisitos do conceito de CRM, ou seja, entender as necessidades, preferências e perfis dos clientes e a frequência com que adquirem serviços e produtos, de forma a economizar todos as informações em um único banco de dados.

A filosofia de CRM é uma combinação da filosofia de marketing de relacionamento, que ensina a importância de cultivar clientes, que através do uso extensivo de

$\mathrm{RC}: 85362$

Disponível em: https://www.nucleodoconhecimento.com.br/marketing/ferramenta-crm 
informações relacionadas à $\mathrm{Tl}$, estabeleça um relacionamento estável e duradouro com eles, fornecendo recursos de informática e telecomunicações de forma única.

O objetivo geral deste trabalho é analisar a importância do CRM na obtenção da fidelização do cliente em um ambiente organizacional. Para realizar a pesquisa, usamos estudos de caso, métodos de observação sistemática e histórica, que são descritos em detalhes neste capítulo. A pergunta-problema que norteou o trabalho foi o CRM é uma opção tecnológica viável para o gerenciamento do relacionamento com o cliente?

O CRM é uma escolha de tecnologia viável e econômica, desde que a organização possa gerenciar o relacionamento com o cliente com compromisso, suporte e controle, com indicadores para monitorar o feedback do cliente e gerar soluções insatisfatórias.

\section{REVISÃO BIBLIOGRÁFICA}

A revisão bibliográfica é a base que sustenta qualquer pesquisa científica. Para proporcionar o avanço em um campo do conhecimento é preciso primeiro conhecer o que já foi realizado por outros pesquisadores e quais são as fronteiras do conhecimento naquela (VIANNA, 2001).

A revisão bibliográfica é um estudo baseado na obra do autor, que descreve o tema da discussão de certa forma de acordo com as normas científicas da ABNT, e determina a cientificidade do conteúdo divulgado e explicado com base nas informações absorvidas.

RC: 85362

Disponível em: https://www.nucleodoconhecimento.com.br/marketing/ferramenta-crm 


\subsection{DEFINIÇÃO DE SERVIÇO}

De acordo com Campos (2014), um produto ou serviço é aquele que atende perfeitamente, de forma confiável, de forma acessível, de forma segura e no tempo certo às necessidades do cliente.

Dada a definição de que um serviço não pode estar associado a um produto, embora não seja esse o objetivo da transação, é compreensível que existem vários tipos de serviços no mercado, eles podem ser diferentes e alguns são mais tangíveis quando associados a produtos físicos do que outros que são essencialmente intangíveis quando não associados a produtos físicos.

De acordo com Las Casas (2006), independente dos tipos ou classificações o resultado final de um serviço é sempre um sentimento, os clientes ficam satisfeitos ou não conforme suas expectativas.

Ao lidar com coisas não óbvias e frequentemente usando alguma informação, esses serviços representam desafios para as empresas que os fornecem, em alguns casos, informações e commodities, isto é, a empresa deve entender os tipos de serviços que presta, ficar de olho no processo e verificar como o processo é executado e os resultados obtidos. Nesse tipo de negociação, existe uma relação direta entre a empresa e o cliente, e a opinião do cliente afetará muito a imagem da empresa.

Segundo Teboul (2008, p. 51) "um serviço é uma sequência de atividades que habitualmente ocorre, ao longo das interações entre estruturas, clientes, recursos humanos, bens e sistemas do provedor, com o objetivo de atender a uma necessidade do cliente". Conforme os referidos autores, o serviço é uma atividade econômica intangível, e as empresas procuram prestar serviços aos clientes de

RC: 85362

Disponível em: https://www.nucleodoconhecimento.com.br/marketing/ferramenta-crm 
forma qualitativa, de forma a obter a satisfação e as expectativas dos clientes, mantendo assim a fidelização e à organização.

\subsection{ABORDAGEM SOBRE O CLIENTE}

Segundo Kotler e Keller (2012), a satisfação do cliente revela o bom funcionamento da empresa de entregar algo que se prometeu, e com o cliente satisfeito é possível criar uma relação, que para a empresa é de grande importância, pois quanto maior essa relação mais chance de o cliente ser fiel.

Para que uma empresa tenha sucesso, ela deve vender o que os clientes desejam comprar e, para isso, deve conhecer suas vontades, necessidades, atitudes e tendências de compra, é preciso manter contato com o cliente e conhecê-lo.

Kotler e Armstrong (2015, p. 7) "afirmam que o valor para o cliente e a satisfação dele são componentes fundamentais do desenvolvimento e da gestão de relacionamento com o cliente".

O foco nas necessidades, desejos e satisfação dos clientes tornou-se o diferencial da empresa, sem eles o funcionamento da organização perderia o sentido, daí a importância de pesquisar e estudar comportamentos, insatisfações e tendências de consumidores.

Porém, é claro que o cliente é a razão da existência da organização, prestar-lhe um serviço de qualidade, ouvir a sua voz, atentar para as suas necessidades e compreender as suas expectativas em relação à empresa, isso está a tornar-se cada vez mais importante para a organização.

Quando os desafios do mercado exigem que as empresas adotem posturas estratégicas relacionadas aos negócios, entender a importância dos clientes é essencial para o crescimento da organização, para que eles tendam a vender mais

$\mathrm{RC}: 85362$

Disponível em: https://www.nucleodoconhecimento.com.br/marketing/ferramenta-crm 
produtos, conquistar novos consumidores e fornecer produtos, serviços e produtos de qualidade.

A lealdade demonstra a relação do cliente com a marca, dificultando que o consumidor consuma outras marcas, mude de produto ou fornecedor. Assim, são denominados como os clientes fiéis, que são aqueles que continuam na empresa refazendo repetidamente suas compras, mesmo precisando ou não daquele serviço ou produto. Porém, para avaliar a fidelidade do cliente é preciso conferir qual a frequência de compra ou se o cliente demonstra desinteresse seja em qualquer procedimento de contato com a empresa (BARRETO; CRESCITELLI, 2013).

O atendimento é algo que toda organização deve valorizar muito para ser reconhecida no mundo dos negócios.

Um cliente bem atendido e considerado valioso espalha isso para outras pessoas para que, a empresa possa conquistar novos clientes, esses novos clientes se esforçam para garantir produtos e serviços de qualidade, bem como um bom atendimento, sendo esse um fator que deve existir em qualquer negócio.

\subsection{MARKETING DE RELACIONAMENTO}

Por volta da década de 1960, o Marketing passou a ser utilizado amplamente na gestão administrativa, e assim suas definições conceituais foram mudando e evoluindo junto com a dinâmica do próprio mercado e comportamento dos consumidores. (GOMES; KURY, 2013).

Nas últimas décadas, o marketing de relacionamento se tornou um princípio de marketing que enfoca os benefícios de relacionamentos duradouros com os clientes como ponto de partida para agir.

Alves (2017, p. 05, apud MADRUGA, 2004) explica:

$\mathrm{RC}: 85362$

Disponível em: https://www.nucleodoconhecimento.com.br/marketing/ferramenta-crm 
...a expressão marketing de relacionamento surgiu timidamente na década de 80 na área acadêmica, que contestava a baixa eficácia do marketing convencional para muitas situações, e atualmente começa a tomar o seu lugar de importância nas organizações. Ele foi influenciado por várias correntes, entre as quais o marketing de serviços, o marketing industrial americano e a qualidade total. Embora esteja apenas na sua "infância", talvez seja um dos temas mais importantes do mundo contemporâneo dos negócios, que efetivamente está auxiliando as empresas a tornarem-se diferentes, próximas de seus clientes, líderes de mercado e altamente rentáveis.

Desta forma, o método de marketing de relacionamento pode trazer benefícios não só para a empresa e para os clientes, mas também para todos os envolvidos no sistema de mercado.

Augusto e Junior (2017, p. 02) "complementam destacando que atender bem ao cliente não é mais simplesmente recepcioná-lo dentro do estabelecimento, não é mais ser cordial ao telefone, ou responder de imediato o seu e-mail”.

Portanto, o conceito de marketing de relacionamento proposto nesta pesquisa mostra que seu objetivo é focar no relacionamento duradouro com os clientes, identificar clientes rentáveis e suas necessidades e fazer recomendações de valor a partir disso, para ser fiel a eles.

Nesse período, o posicionamento da empresa não é mais apenas vender sem se preocupar com a satisfação do consumidor, mas construir uma empresa que esteja mais atenta às suas necessidades e desejos, e estabelecer um relacionamento duradouro como diferencial competitivo no mercado.

No processo de marketing de relacionamento, a empresa deve utilizar o processo de feedback e informações relacionadas à fidelização para focar na promoção da integração de seus interesses e necessidades do cliente.

Seu principal objetivo é manter a empresa informada sobre o perfil de seus clientes e suas necessidades e expectativas específicas.

RC: 85362

Disponível em: https://www.nucleodoconhecimento.com.br/marketing/ferramenta-crm 
Desse modo, a qualidade é uma ferramenta importante para competir no mercado do século XXI. Não basta vender produtos ou serviços a preços atrativos, é preciso fortalecer a relação entre fornecedores e clientes.

\subsection{CUSTOMER RELATIONSHIP MANAGEMENT - CRM}

Em geral, a literatura de CRM cita dois métodos de origem e evolução de CRM. O primeiro método envolve o desenvolvimento de ferramentas técnicas para integrar várias funções da organização.

O segundo método discute o desenvolvimento da tecnologia de gestão empresarial, que visa integrar as áreas internas da empresa com diferentes finalidades: controle de estoque, custo e lucratividade. São os chamados sistemas de Enterprise Resollrce Planning (ERP).

Do ponto de vista técnico com foco em marketing, o CRM pode ser entendido como uma melhoria em várias outras tecnologias desenvolvidas nas últimas décadas, mas há uma grande diferença.

Surgem como diferencial competitivo as estratégias de CRM.

O objetivo do CRM é coletar informações sobre os clientes. Essa ferramenta auxilia as decisões de marketing de relacionamento de uma empresa junto aos seus clientes. A data base de marketing possibilita 0 conhecimento sobre os clientes, prevendo comportamentos. O uso adequado desses dados depende de uma política de relacionamento da empresa com os consumidores, aumentando as oportunidades de oferecer aos clientes o produto certo. (SWIFT, 2014).

No Brasil, o CRM foi lançado em 1995 e atingiu crescimento anual de dois dígitos, as empresas distribuidoras de CRM descobriram mercados potenciais enquanto os executivos estão ansiosos para integrar novas tecnologias, assim como aconteceu nos call centers no início dos anos 1990, e na Internet em meados dos anos 1990, o

RC: 85362

Disponível em: https://www.nucleodoconhecimento.com.br/marketing/ferramenta-crm 
Brasil rapidamente se tornou um dos maiores mercados de investimento em tecnologia do mundo.

Com o passar do tempo, o pacote de aplicativos de CRM orientado ao cliente foi integrar vários departamentos para formular estratégias de marketing - adquira novas funções, integrando-se com a internet e expandindo o número de canais para relacionamento com clientes.

A chave do relacionamento é a informação, conhecer o cliente é essencial para a empresa e administrar um grande volume de informações não é tarefa fácil, a utilização da Tecnologia de Informação (a partir deste ponto citada como TI) para a formação de bancos de dados, é um sistema de apoio indispensável para uma grande organização, mas esta é apenas uma das bases para o desenvolvimento do CRM. (SWIFT, 2014).

A satisfação e verificação das necessidades do cliente são fundamentais para a sobrevivência de uma organização, independentemente do seu âmbito de atividades ou natureza das operações, sejam prestadores de serviços e / ou empresas, os fatores que definem o sucesso e o fracasso da organização são seus clientes.

\subsubsection{VANTAGENS E OBJETIVOS DO CRM}

Muitos dos objetivos do CRM foram abordados neste capítulo e no capítulo anterior, mas não foram abordados diretamente.

Agora, vamos abordar diretamente esses objetivos, explicando-os.

Conforme Fellipini (2016, p. 1), diz que: “[...] o objetivo não é apenas conhecer melhor o cliente, mas, principalmente, buscar de forma incessante o atendimento de suas necessidades de forma que a satisfação desse cliente se transforme em

RC: 85362

Disponível em: https://www.nucleodoconhecimento.com.br/marketing/ferramenta-crm 
fidelidade à marca". Podemos citar três pontos como objetivos principais do CRM. São eles:

- Retenção de clientes: melhorar (aumentar) a capacidade de reter os clientes atuais da empresa e capacitar a empresa a manter os canais lucrativos, de modo a aumentar a lucratividade.

- Obtenção de clientes: definir quais são os melhores clientes, com base em características já conhecidas ou novas características, que terminam por levar ao crescimento.

- Lucratividade por cliente: aumento das margens individuais dos clientes e, ao mesmo tempo, a capacidade de ofertar o produto/serviço certo na hora certa.

Além desses objetivos gerais, também podemos incluir alguns objetivos específicos, dependendo do status de desenvolvimento da empresa:

- Reconquistar ou Salvar: este é o processo que tenta convencer um cliente a ficar com a empresa quando ele a está abandonando ou recuperar um cliente que já tenha sido perdido.

- Busca de clientes em potencial: também conhecido como prospecting, este processo é a busca por novos clientes, com os quais a empresa nunca tenha lidado. Neste tipo de processo, três elementos

- São fundamentais: a segmentação, a seletividade e as fontes. A segmentação é fundamental, pois permite à empresa uma concentração efetiva na oferta. Quanto melhor for a segmentação, menor o risco de rejeição dos clientes.

- Vendas Cruzadas/Up-Selling: estes mecanismos são utilizados para aumentar os investimentos dos clientes na empresa. O objetivo é identificar outros produtos e serviços que o cliente gostaria de comprar (vendas cruzadas) ou adicionar alguns incrementos às ofertas do cliente (up-selling).

RC: 85362 
Nesta seção será apresentada as vantagens que a ferramenta CRM tem encontrados na literatura.

Bretzke (2000), relaciona uma lista de possíveis benefícios que podem ser conseguidos com a implementação de um sistema CRM, são eles:

- Aumentar o conhecimento sobre o cliente;

- Reduzir os custos operacionais que envolvam a venda dos produtos/serviços;

- Obter diferencial de produtos/serviços dos concorrentes, entendendo a necessidade do cliente;

- Aprimorar os produtos/serviços entregues conforme a mudança de mercado;

- Elevar a fidelização e retenção de clientes;

- Redução no tempo de resposta a divergências com clientes;

- Compilar e transmitir informações com maior velocidade e segurança dentro da organização.

\subsubsection{ESTRATÉGIAS DE CRM}

De acordo com os comentários preliminares feitos neste trabalho, pode-se observar que entre as várias opiniões disseminadas na pesquisa acadêmica e na prática empresarial, o CRM (Customer Relationship Management) surgiu como uma estratégia que visa entender e prever as necessidades dos clientes atuais e potenciais da organização.

Para Wenningkamp (2016, p. 1), “como conceito: CRM é uma estratégia de negócio voltada ao entendimento e antecipação das necessidades e potenciais de uma empresa". Como objetivo principal, um sistema CRM tende a ser uma ferramenta para auxiliar a fidelização de clientes, porém, apesar de apresentar um resumo autoexplicativo, não é tão fácil como parece, pois, é preciso buscar a satisfação total

RC: 85362

Disponível em: https://www.nucleodoconhecimento.com.br/marketing/ferramenta-crm 
do cliente, antecipar desejos, necessidades, e oferecer produtos ou serviços adequados ao cliente.

Portanto, pode-se perceber que o CRM parece ser um processo organizacional que permite uma gestão eficaz do relacionamento com os clientes.

Nesse caso, expor e observar os diversos conceitos de CRM propostos na literatura fazem parte das recomendações desta pesquisa.

Nesse aspecto, Bull (2003), alerta que o CRM tem significados diferentes para mentes diferentes, representando coisas distintas.

O autor analisa algumas concepções sobre CRM e afirma que o CRM representa uma combinação complexa de fatores de negócio e tecnologia, ressalvando que as estratégias devem ser formuladas conforme esses fatores.

Também destacam o papel positivo dos clientes na tomada de decisões organizacionais por meio de sugestões ou críticas ao longo do relacionamento, eles enfatizam que os clientes são sempre o ponto de partida, embora os clientes lucrativos devam ser identificados para que possam se tornar esse marco. $O$ autor também enfatizou o relacionamento com os parceiros e a necessidade de concretizar a visão de "network" (trabalho em rede) da estratégia de CRM. Eles acreditam que as organizações precisam de parceiros para personalizar o atendimento ao cliente.

De modo similar, Bretzke (2000), acredita-se que o CRM é a integração entre o marketing e a tecnologia da informação, que visa proporcionar às empresas uma forma mais eficaz e integrada de prestar serviços em tempo real, identificar e atender os clientes, portanto, transformar esses dados em informações veiculadas pela organização permite que toda a empresa entenda e cuide dos clientes.

RC: 85362

Disponível em: https://www.nucleodoconhecimento.com.br/marketing/ferramenta-crm 
Segundo a autora, o uso de tecnologia de informação avançada para capturar centralmente esses dados no banco de dados de marketing pode entender o perfil dos clientes, e detectar ameaças e oportunidades emitidas por reclamações (ameaças), solicitando mais informações.

Existem diferenças entre os concorrentes (ameaça), o que implica que os concorrentes estão prestando mais serviços (ameaça) ou os clientes estão abrindo outro departamento de produção (oportunidade).

\subsubsection{FASES DA IMPLANTAÇÃO DO CRM}

O CRM deve ser implementado sem uma estratégia orientada para o cliente, porque o objetivo do CRM não é criar, mas apoiar e implementar estratégias orientadas para o cliente. As empresas que investem em CRM acreditam que o sistema estabelecerá a estratégia da empresa e desperdiçará tempo e dinheiro.

Isso significa que o primeiro passo em qualquer esforço para implementar uma solução de CRM é desenvolver uma estratégia eficaz para os clientes, ou seja, definir os tipos de clientes necessários, como encontrá-los e como prestar serviços aos clientes, como meio de comunicação preferido (e-mail, fax, telefone, Internet etc.), frequência e método de contato com os clientes etc.

Segundo o embasamento de Novello (2013, p. 11) "a implantação de um sistema CRM em uma empresa tem a intenção de melhorar o seu relacionamento com o cliente, não só no momento da venda, mas em todo o ciclo de vida deste cliente com a empresa".

Trata-se de um processo holístico para antecipar e satisfazer as expectativas dos clientes. O autor acrescenta que as capacidades analíticas são extremamente importantes para o desenvolvimento da função.

RC: 85362

Disponível em: https://www.nucleodoconhecimento.com.br/marketing/ferramenta-crm 
Bretzke (2000), afirma que se deve evitar a tendência de tratar CRM como tecnologia e recomenda que a empresa assuma a estratégia de CRM em quatro etapas:

A definição e plano do modelo de relacionamento: Definir como tratar os clientes, os eventos que irão produzir uma resposta, quando e como desenvolver um plano de comunicação para estabelecer um relacionamento e fornecer uma empresa de valor recomendado para uma estratégia competitiva. Esta etapa é muito importante porque o processo precisa ser redesenhado e customizado, e o software depende desta configuração. A alta administração participa dessa etapa porque ela implica uma série de decisões que determinarão mudanças nas atitudes do cliente.

Redesenhar o processo de atendimento ao cliente: É a investigação e registro do processo de atendimento ao cliente, incluindo solicitações de acesso, serviços telefônicos, televendas ou reclamações. Nessa etapa também são levantados os recursos de Tecnologia de Informação ( $\mathrm{TI})$ necessários. O redesenho do processo pode ser muito demorado e caro, mas a empresa deve passar por essa fase porque $80 \%$ dos implantes falham a falta de CRM se deve à falta de planejamento.

Seleção da solução: A decisão da solução de CRM inclui a escolha do software, que é determinada pelo modelo relacional. Por sua vez, o software determinará o melhor hardware que constitui a solução.

Tecnologia de CRM: técnicas, tecnologias e processos para implementar a estratégia de CRM. A empresa deve garantir que todas as atividades de contato com o cliente sejam incluídas no marketing e no monitoramento do banco de dados antes do final do ciclo de relacionamento.

As quatro etapas da implantação do CRM citadas estão representadas na Figura 1:

RC: 85362

Disponível em: https://www.nucleodoconhecimento.com.br/marketing/ferramenta-crm 
Figura 1: Etapas da implantação da estratégia de CRM

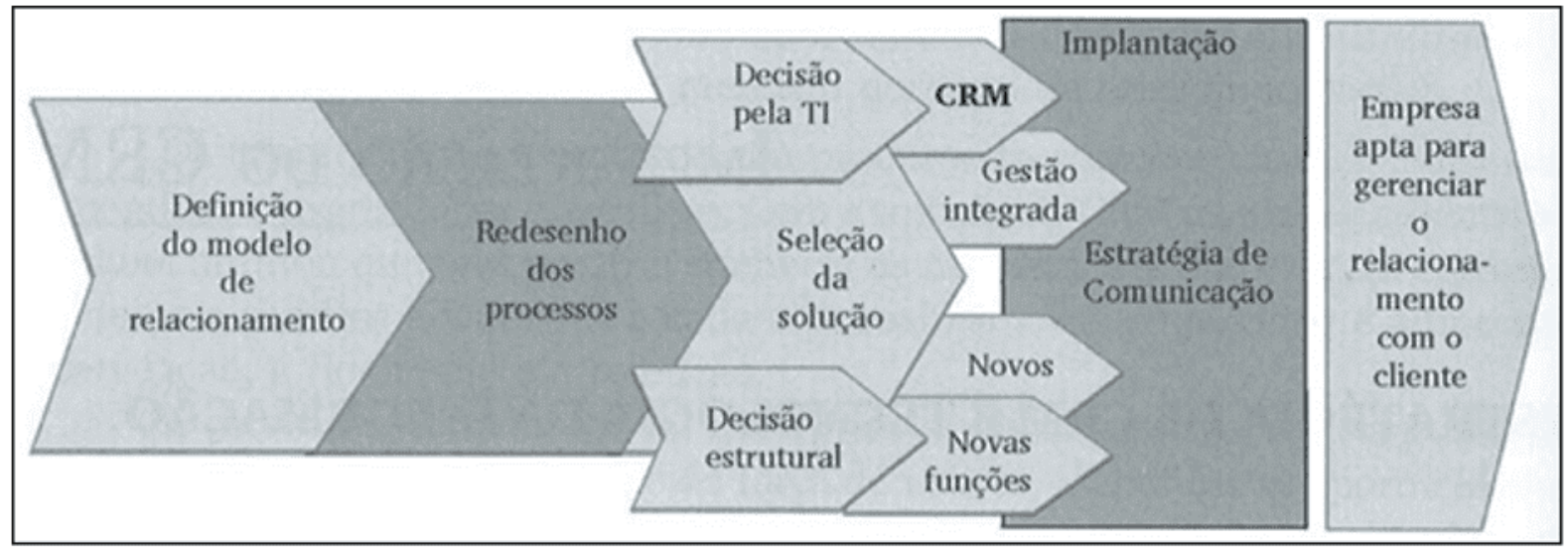

Fonte: Bretzke (2000).

Já Madruga (2006), entende que as empresas necessitam de uma metodologia para a implantação segura do CRM. O caminho está dividido em oito etapas, conforme apresentado na Figura 2:

Figura 2: Oito etapas para a implantação do CRM

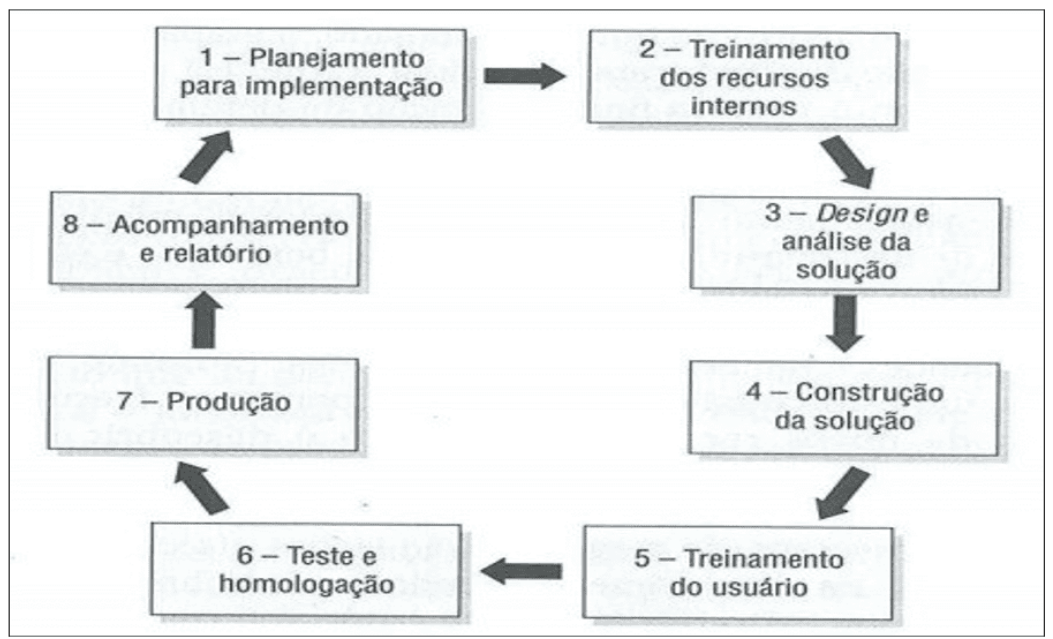

Fonte: Madruga (2006).

RC: 85362

Disponível em: https://www.nucleodoconhecimento.com.br/marketing/ferramenta-crm 
As etapas de implantação do CRM sugeridas por Madruga (2006), demonstradas na Figura 2 estão detalhadas a seguir:

1. planejamento para a implantação: planejamento para a implantação: essa etapa envolve a prospecção de pessoas para o projeto, formar uma equipe com integrantes das duas partes e confeccionar cronograma inicial;

2. treinamento dos recursos internos: treinam-se previamente os recursos de $\mathrm{TI}$ e apenas alguns usuários chaves, como forma de garantir que serão participativos e colaborativos durante a fase de implantação;

3. design e análise da solução: definição de telas de trabalho, criação dos processos e fluxos de informação, definição dos relatórios e dimensionamento de hardware. Mapear quem é indispensável no projeto, definir o escopo e levantar os macroprocessos de negócios são ações típicas dessa fase;

4. construção da solução: conforme o que foi levantado na etapa anterior, a solução começa a ser customizada para se adequar às necessidades da empresa;

5. treinamento do usuário final: trata-se de uma das fases mais importante, pois até então, o usuário apenas participou do teste do CRM e não tem uma ideia clara de como será seu trabalho com o novo sistema. O treinamento reflete tudo que está aprovado e ocorre normalmente com dedicação total;

6. teste de homologação do que foi construído: é feita a validação junto ao usuário, a fim de verificar se as entregas estão de acordo com o projeto, isto, é, se as "promessas" realizadas na fase inicial da proposta foram cumpridas;

7. fase de produção: a empresa já opera a solução nessa etapa. São realizadas rotinas de backup para garantir a segurança dos dados;

8. acompanhamento da produção e relatório final: ocorre o ajuste de performance do sistema quanto ao tempo de resposta. Os pontos de melhoria e os cuidados necessários para o funcionamento correto do CRM são 
condensados com o usuário. O relatório final tem como objetivo a melhoria contínua da aplicação de CRM.

Quando a estratégia centrada no cliente é definida, a empresa deve garantir que ela seja implantada. Os funcionários devem ser treinados e motivados a trabalhar com a estratégia selecionada. Praticamente, eles devem ser capazes de resolver problemas de clientes e trabalhar com a nova informática. Outra tarefa importante é conectar aplicativos existentes ao novo sistema CRM. Dependendo da solução atual da empresa, esta tarefa pode variar de uma simples tentativa de desenvolvimento geral de novas aplicações que interagem entre o CRM.

\section{MATERIAIS E MÉTODOS}

A metodologia fornece suporte teórico para o tema de trabalho, a fim de atingir os objetivos pré-determinados da pesquisa, sendo uma explicação detalhada, minuciosa, rigorosa e precisa de cada ação desenvolvida no método de trabalho de pesquisa.

Então, por exemplo, esta é uma explicação do tipo de pesquisa, dos equipamentos utilizados, do tempo de previsão e do processamento dos dados, portanto, os aspectos metodológicos selecionados para a pesquisa precisam esclarecer as etapas percorridas na pesquisa e os meios norteadores para o alcance dos resultados da pesquisa.

Para Libório e Terra (2015, p.15) "o método científico pode ser definido como um conjunto de regras básicas empregadas em uma investigação científica, com o objetivo de obter resultados, de forma imparcial e confiável".

No entanto, o projeto contará com diferentes ferramentas e métodos que ajudarão a identificar as soluções da VAP Informática Ltda. Finalmente, é importante definir o que representa o problema de acordo com o conceito das ferramentas do CRM.

RC: 85362

Disponível em: https://www.nucleodoconhecimento.com.br/marketing/ferramenta-crm 


\subsection{PROCEDIMENTOS METODOLÓGICOS}

Os procedimentos metodológicos são a classificação da pesquisa, cujo objetivo é definir os métodos e formas a serem utilizados no decorrer desta pesquisa.

Quando pesquisadores e participantes que representam situações ou problemas participam de forma cooperativa ou participativa, esta pesquisa tem características próprias.

Vale destacar que o conhecimento do senso comum também produz conhecimento, mas para este trabalho, o conhecimento a ser citado é científico, pois como cita Minayo (2014, p.35)

na sociedade ocidental, a ciência é a forma hegemônica de construção do conhecimento, embora seja considerada por muitos críticos como um novo mito da atualidade, conhecimento, embora seja considerada por muitos críticos como um novo mito da atualidade, por sua pretensão de único promotor e critério de verdade.

\subsubsection{QUANTO À NATUREZA}

A natureza da pesquisa envolve o propósito e a contribuição que trará para a empresa, devido ao propósito de ampliar o campo do conhecimento, esta pesquisa atende a natureza básica.

De acordo com o quadro de perguntas realizado nas áreas da empresa citada, foi realizado um estudo quali-qualitativo, obtendo-se um determinado percentual de problemas na área de marketing da VAP Informática Ltda.

Segundo Knechtel (2014, p. 91)

a pesquisa quantitativa é uma modalidade de pesquisa que atua sobre um problema humano ou social, é baseada no teste de uma teoria e composta por variáveis quantificadas em números, as quais

RC: 85362

Disponível em: https://www.nucleodoconhecimento.com.br/marketing/ferramenta-crm 
são analisadas de modo estatístico, com o objetivo de determinar se as generalizações previstas na teoria se sustentam ou não.

O autor alerta que a pesquisa qualitativa é diferente da pesquisa quantitativa, pois a pesquisa quantitativa visa seguir estritamente o plano previamente formulado, enquanto a pesquisa qualitativa enfoca todo o processo de desenvolvimento e não busca medir eventos ou utilizar ferramentas estatísticas para análise de dados.

A pesquisa qualitativa obtém dados descritivos por meio da conexão direta e interativa entre o pesquisador e a situação de pesquisa, por esse motivo, os pesquisadores costumam tentar compreender o fenômeno no campo de visão dos participantes em situação de pesquisa.

\subsubsection{QUANTO AOS FINS}

Com relação aos fins, trata-se de um estudo qualitativo descritivo. A pesquisa descritiva visa melhorar a prática por meio da observação, análise e descrição por meio de entrevistas, por exemplo, a fim de encontrar soluções para problemas.

Dizia Vergara (2016, p. 74) "a pesquisa descritiva expõe características de determinada população ou de determinado fenômeno".

Pode também estabelecer correlações entre variáveis e definir sua natureza. Não tem compromisso de explicar os fenômenos que descreve, embora sirva de base para tal explicação.

\subsubsection{QUANTO AOS MEIOS}

Quanto aos meios, baseia-se na pesquisa bibliográfica, através da coleta de dados junto aos gestores e diretores da empresa VAP Informática Ltda, pelo acesso ao banco de dados, desde as observações no dia da visita, até coletar todas as informações e atingir o objetivo final.

RC: 85362

Disponível em: https://www.nucleodoconhecimento.com.br/marketing/ferramenta-crm 
Para Callado e Ferreira (2004, p. 03) "os espaços de pesquisa são orientados pela própria natureza do estudo, portanto, a localização dos documentos pode ser muito diversificada". Essa distinção vai exigir que o pesquisador tenha conhecimento do tipo de registro e informações que abrigam as instituições visitadas e a seleção de fontes adequadas.

\subsection{CARACTERIZAÇÕES DA EMPRESA}

A história da Vap Informática LTDA se inicia quando o amazonense Paulo Egídio começou o início de um sonho, assim fundando a empresa que inicialmente trabalhava somente prestando serviço de hardware (manutenção em computadores e impressoras).

No ano de 2004 a empresa lançou no mercado seu software (Vapgest), credenciado junto a Sefaz-AM para emissão de cupom fiscal, e começou a trabalhar como representante da marca de impressora fiscal SWEDA, crescendo no mercado e conquistando muitos clientes com seu software intuitivo fácil de usar, e como representante da marca SWEDA, também conquistou muitos clientes como Supermercados DB e Lojas Bemol entre outros.

Em 2009 a empresa alcançou a marca de seus 1000 cliente usando seu software é uma das empresas mais indicadas dentro da Sefaz-AM, sendo assim a Vap já tinha seus setores divididos como, financeiro, recursos humanos, TI, assistência técnica e recepção, nesse momento a empresa chegava a ter 32 funcionários divididos nesses setores.

No ano de 2012 a empresa lança o sistema de Speed fiscal por ver a necessidade de alguns de seus clientes que tinham faturamento mensal altos, assim facilitando as informações que eram passar para seus contadores, seguindo a inovação do sistema de Sped fiscal, no ano de 2013 a Sefaz do estado do amazonas lança no

RC: 85362

Disponível em: https://www.nucleodoconhecimento.com.br/marketing/ferramenta-crm 
mercado a nova ideia de software que seria os sistema de NFC-e (Cupom Eletrônico) e o NF-e (Nota Fiscal Eletrônica), que seria a ideia de enviar automaticamente as notas emitidas para um servidor dentro da Sefaz, mesmo com esse novo sistema, as impressoras fiscais ainda continuariam no mercado para venda por mais um ano, e para os que já usavam poderiam usar por mais dois anos a partir do ano de 2013 ou seja até 2015.

No início de 2014 a empresa se muda para sede própria que se encontra na rua diamante $\mathrm{N}^{\circ} 03$, conjunto manauense, bairro nossa senhora das graças.

Também no final de 2014 a empresa sofreu com a crise que chegou em todo Brasil, assim perdendo alguns clientes de manutenção, que com o tempo se vendo necessário diminuir o seu quadro de funcionário de 32 para 26 , até por que quando chegou o ano de 2015 às impressoras fiscais pararam de ser usadas e comercializadas, tirando do mercado um dos carros chefes da empresa.

No final do ano de 2015, o diretor da empresa passou a empresa para o nome dos seus filhos Ana Caroline Corrêa da Silva e Paulo Egídio Ribeiro da Silva Junior e começou um novo ciclo, novos produtos para comercializar (leitores de código de barras, gavetas de dinheiro, impressoras térmicas, impressoras térmicas de etiqueta).

Em 2018 a Vap inova mais uma vez agregando a seu software o sistema Mobile para restaurante e vendas externas (sistema no celular Android), e para seus clientes de restaurante foi feito uma promoção para os que gostariam de adquirir o módulo Mobile.

E no início desse ano de 2020, deu-se início a um novo projeto que é ter o sistema para seus clientes $100 \%$ em um servidor nas nuvens, assim possibilitando seus clientes acessarem seu sistema, relatórios e informações de qualquer lugar, necessitando somente de um computador e internet.

RC: 85362

Disponível em: https://www.nucleodoconhecimento.com.br/marketing/ferramenta-crm 


\section{RESULTADOS E DISCUSSÕES}

De acordo com a pesquisa na fase de diagnóstico organizacional, verifica-se que a Vap Informática Ltda possui pontos fundamentais no campo organizacional, conforme mostrado no Gráfico 01: Medição de Desempenho.

Gráfico 01: Medição de desempenho.

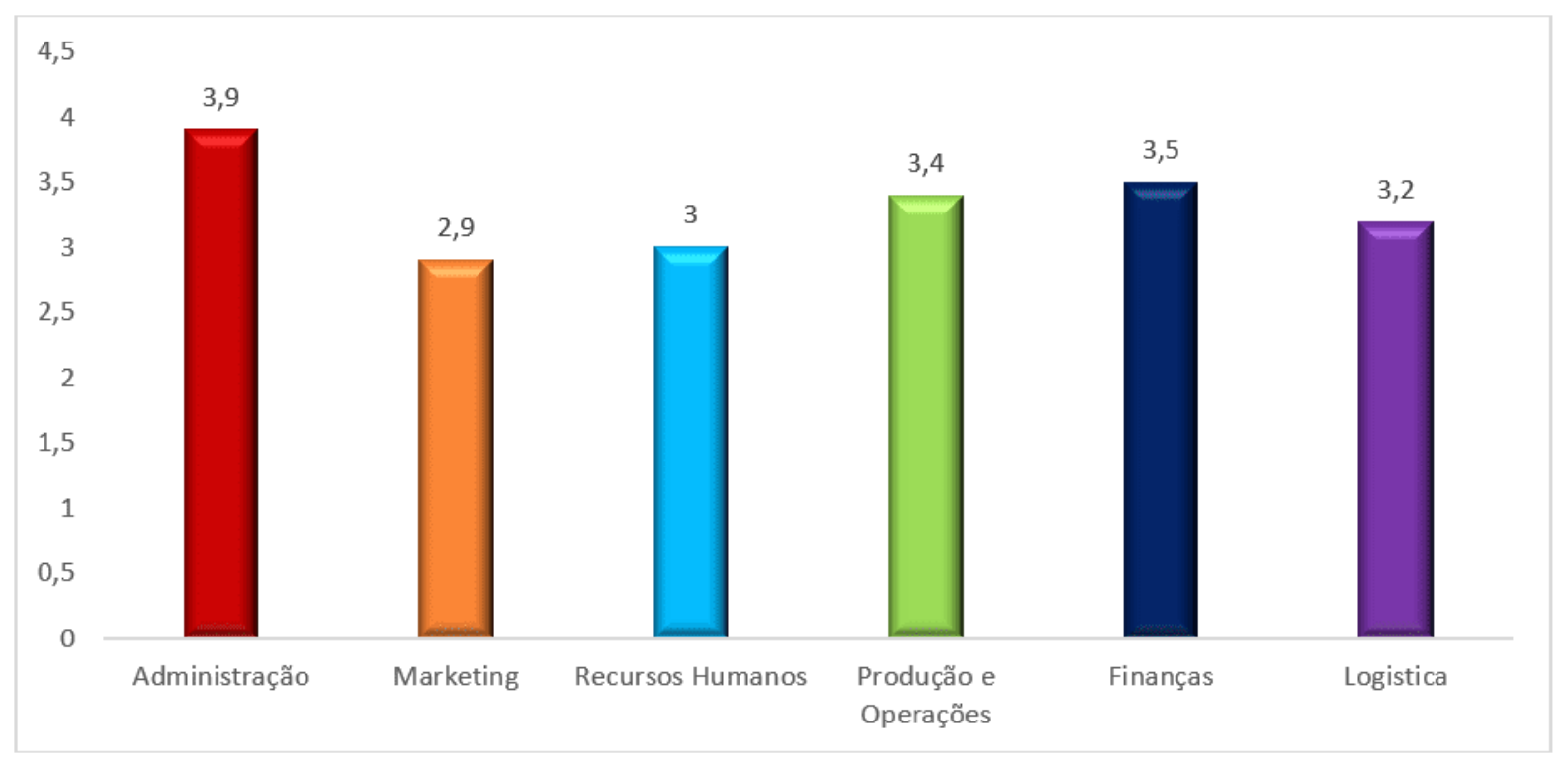

Fonte: Elaborado pelos autores com base na coleta de dados, 2020.

Observa-se que as áreas com melhor desempenho são administração, produção e finanças, logo, as áreas de logística e recursos humanos são áreas de desempenho médio. Marketing com percentual de 2,9 é considerada a área mais crítica, conforme abaixo Quadro 01: Marketing.

RC: 85362

Disponível em: https://www.nucleodoconhecimento.com.br/marketing/ferramenta-crm 
Quadro 01: Marketing.

\begin{tabular}{|c|c|c|c|c|c|}
\hline \multirow[b]{2}{*}{ MARKETING } & \multicolumn{5}{|c|}{ NIVEL OU GRAU DE AVALIAÇÃO } \\
\hline & $\begin{array}{c}\text { PONTO MUITO } \\
\text { FORTE }\end{array}$ & $\begin{array}{l}\text { PONTO } \\
\text { FORTE }\end{array}$ & $\begin{array}{l}\text { PONTO } \\
\text { MÉDIO }\end{array}$ & $\begin{array}{l}\text { PONTO } \\
\text { FRACO }\end{array}$ & $\begin{array}{c}\text { PONTO MUITO } \\
\text { FRACO }\end{array}$ \\
\hline 1 Qualidade dos produtos ou serviço reconhecida pelo mercado & & $\mathrm{x}$ & & & \\
\hline 2 Padronização do produto & & & & & $\mathrm{x}$ \\
\hline 3 Variedade de produtos ancora & & & & $\mathrm{x}$ & \\
\hline 4 Há empresa possui preços competitivos com o mercado & & & $\mathrm{X}$ & & \\
\hline 5 Há localização da empresa favorece a prospecção das vendas & & $\mathrm{x}$ & & & \\
\hline 6 Há empresa possui estratégias de comunicação visual & & & & $\mathrm{x}$ & \\
\hline 7 Há empresa possuem estratégias de divulgação de produtos e serviços & & & & & $x$ \\
\hline 8 Produtos inovadores e diferenciados & & & & & $\mathrm{x}$ \\
\hline 99 Há empresa possui políticas estruturadas de captação de clientes & & $\mathrm{x}$ & & & \\
\hline 10 Satisfação dos clientes ou Cidadãos & & & $\mathrm{x}$ & & \\
\hline 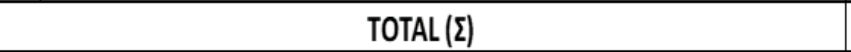 & 5 & 12 & 9 & 2 & 2 \\
\hline MÉDIA POR GRAU (POR COLUNA) & 0,5 & 1,2 & 0,9 & 0,2 & 0,2 \\
\hline 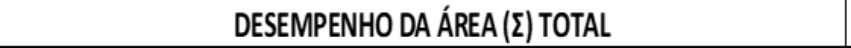 & & & 2,9 & & \\
\hline
\end{tabular}

Fonte: Elaborado pelos autores com base na coleta de dados, 2020.

Conforme dados coletados na pesquisa de campo, por meio de avaliação de documentos, conversa com equipe Vap, foi constatado que a área funcional do setor de marketing há muitos pontos fracos que necessitam de melhorias para o seu melhor funcionamento operacional.

O quadro 1 mostra as funções dos processos dentro da organização. No quadro, podem ser detectadas não conformidades nesta área, que precisam ser melhoradas para garantir a qualidade dos serviços prestados aos clientes finais.

Diante dos resultados, recomenda-se realizar ações de acompanhamento para solucionar os problemas levantados, a fim de buscar a melhoria contínua da atuação na área de marketing. Recomenda-se que a empresa continue a manter sua capacidade de entender o mercado e manter seus métodos de pesquisa para obter conhecimento do mercado.

RC: 85362

Disponível em: https://www.nucleodoconhecimento.com.br/marketing/ferramenta-crm 


\subsection{PLANEJAMENTO DE AÇÕES}

De forma a implementar a solução melhorada, foi desenvolvida uma tabela com ações ativas para intervir nas ações dos serviços prestados pelos colaboradores.

Quadro 2: Atividades Propostas

\begin{tabular}{|c|c|c|c|c|}
\hline Item & Ações Interventivas & Precedentes & Duração & Custo \\
\hline 01 & $\begin{array}{l}\text { Organização dos meios } \\
\text { de divulgação da } \\
\text { empresa }\end{array}$ & $\begin{array}{l}\text { Sem meios de } \\
\text { divulgação }\end{array}$ & 1 dia & $R \$ 150,00$ \\
\hline 02 & $\begin{array}{l}\text { Identificar qual o público- } \\
\text { alvo da empresa }\end{array}$ & $\begin{array}{l}\text { Sem um público } \\
\text { específico }\end{array}$ & 1 dia & $R \$ 150,00$ \\
\hline 03 & $\begin{array}{l}\text { Buscar meios } \\
\text { divulgação } \\
\text { empresa }\end{array}$ & & 1 dia & $\begin{array}{l}\text { Rádio:1 min } \\
\mathrm{R} \$ 650,00 \text { a cada } \\
\text { duas semanas }\end{array}$ \\
\hline 04 & $\begin{array}{l}\text { Treinamento para } \\
\text { vendedores } \\
\text { atendentes }\end{array}$ & $\begin{array}{l}\text { Melhoria no } \\
\text { atendimento }\end{array}$ & 5 dias & $R \$ 500,00$ \\
\hline \multicolumn{4}{|c|}{ TOTAL DE RECURSOS } & $R \$ 1.450,00$ \\
\hline
\end{tabular}

Fonte: Elaborado pelos autores com base na coleta de dados, 2020.

As atividades sugeridas no quadro acima visam aprimorar e corrigir questões consideradas vitais para a VAP Informática Ltda. Com o objetivo de aprimorar os serviços prestados pelos colaboradores, tornar o processo eficiente e de alta qualidade.

RC: 85362

Disponível em: https://www.nucleodoconhecimento.com.br/marketing/ferramenta-crm 


\subsubsection{IMPLEMENTAÇÃO DO CRM}

A ferramenta de CRM selecionada é um modelo gratuito disponível na Internet, e chamamos de "Software de CRM". Esta ferramenta é totalmente focada nas atividades de vendas da organização, portanto, a diferença básica do sistema CRM convencional é que o sistema trabalha com informações sobre clientes, cadastros de produtos e fornecedores; em um mesmo software, todas essas funções juntas registram todas as atividades do processo de vendas da organização.

Figura 1: Tela inicial do sistema "CRM Software"

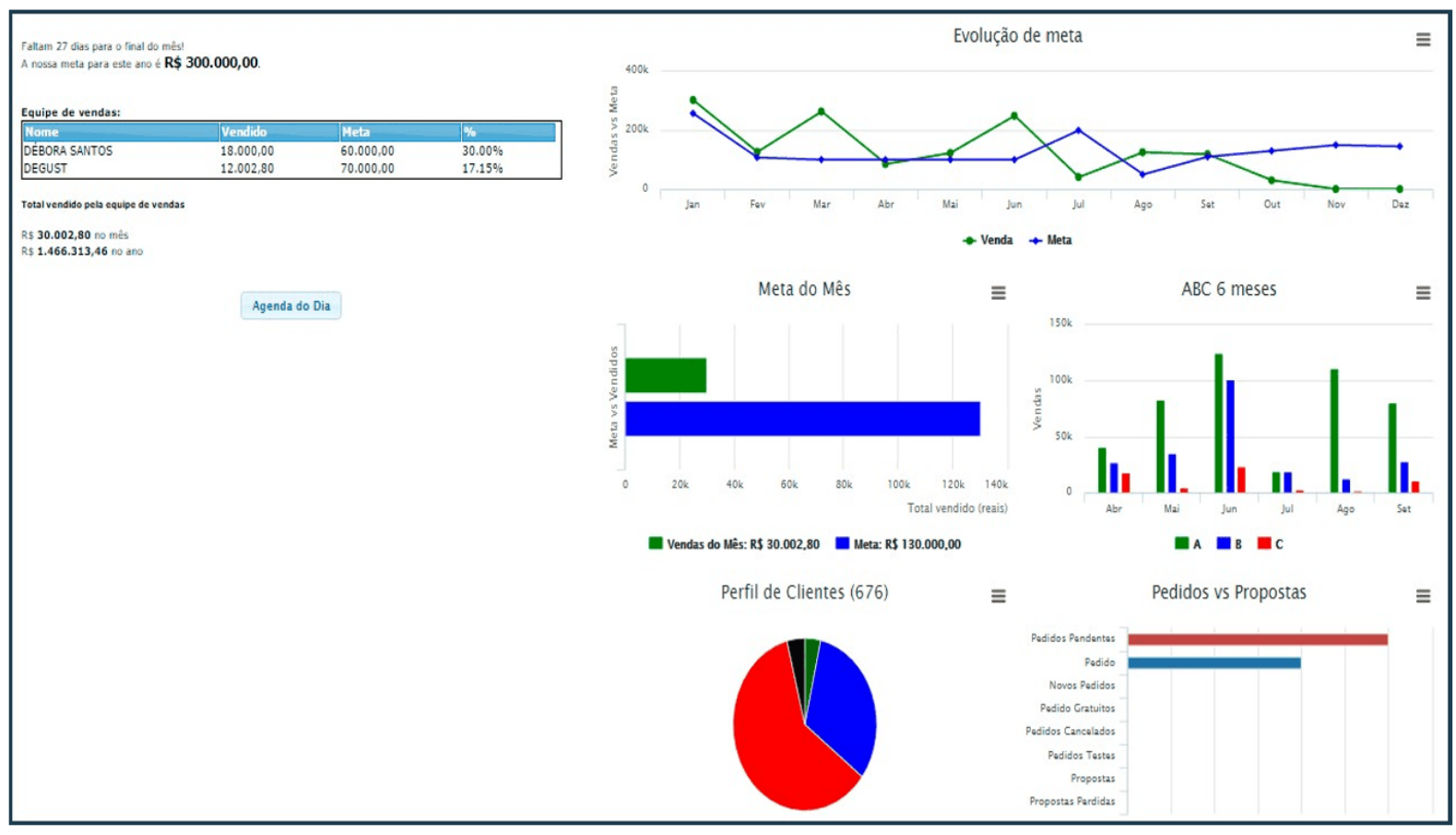

Fonte: CRM Software, 2021.

Ao acessar o sistema, a primeira mensagem exibida é quantos dias faltam para o final do mês. Depois disso, descreve a renda pessoal de cada vendedor, compara o valor da renda com a meta do mês e mostra quanto ainda resta para atingir os objetivos e metas pessoais e gerais da empresa. Na mesma tela, conforme

RC: 85362

Disponível em: https://www.nucleodoconhecimento.com.br/marketing/ferramenta-crm 
mostrado na Figura 1, compara a renda diária com as metas diárias para verificar se estão abaixo ou acima das metas prescritas.

Ainda há um breve resumo durante este período, pendências e ordens de venda finais, todas as informações relacionadas à produção da equipe de vendas.

Desde a primeira ligação para o cliente, o sistema fornece informações sobre todas as vendas da empresa.

O sistema traz as seguintes informações: vendas, pedidos pendentes (não entregues e / ou pagamento), novos pedidos (número e valor dos clientes ativos no período), pedidos cancelados (por erro de produção ou vencidos) até retiradas do cliente, pedido gratuito (doação), proposta (orçamento detalhado), produtos vendidos e valor, produtos de estoque, comparação de valor, comparação de valor de vendas mensais, para que possa comparar um mês com o outro, e perceber quais os meses que foram oferecidos descontos aos clientes, conforme mostrado na figura 2.

$\mathrm{RC}: 85362$ 
Figura 2: Dados do sistema "CRM Software"

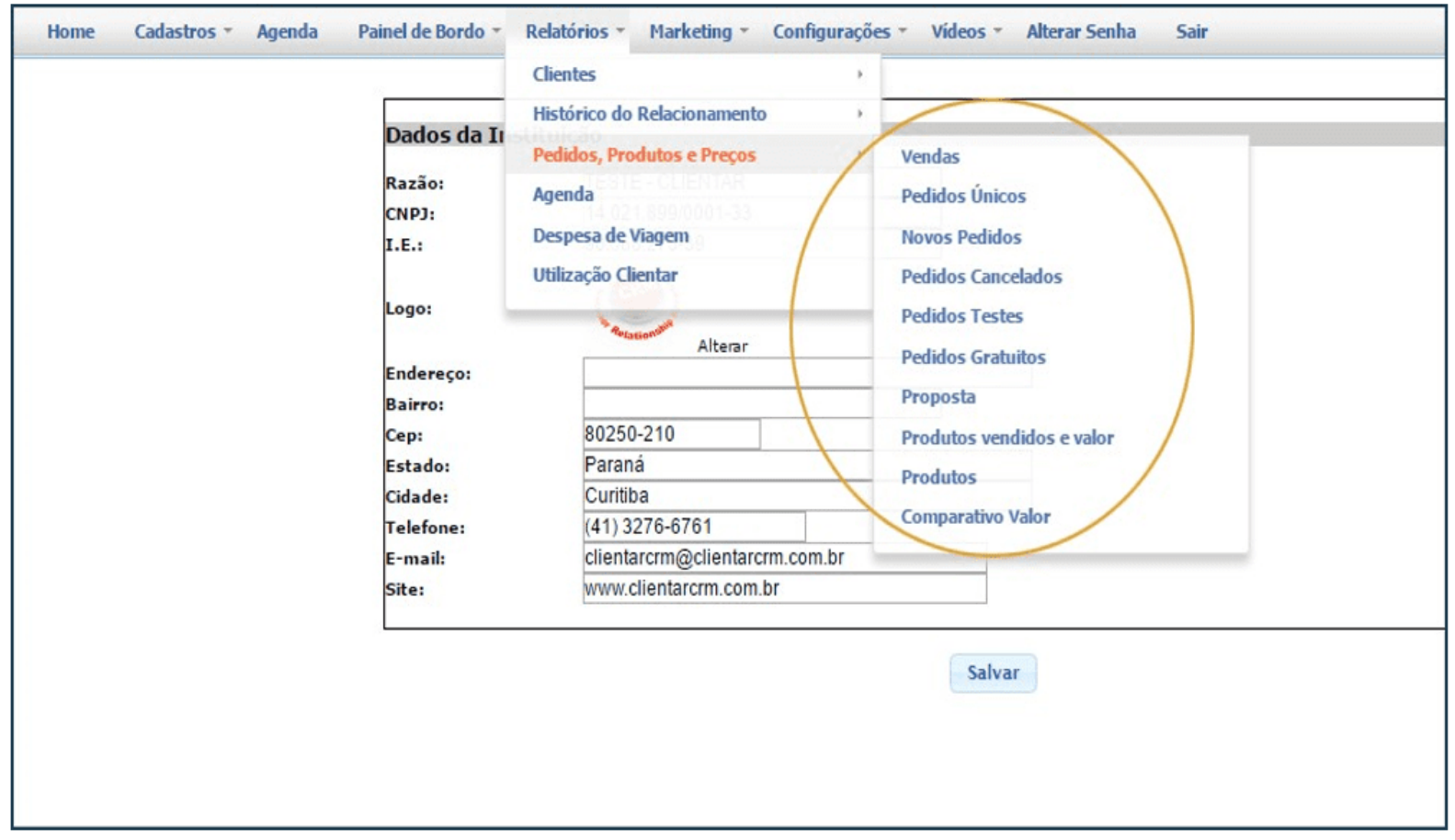

Fonte: CRM Software, 2021.

Na Figura 3, essas informações são resumidas na forma de um gráfico para mostrar a evolução das ações associadas a esses registros. Esses gráficos mostram a porcentagem de vendas, pedidos e orçamento.

Portanto, todos esses contatos dos clientes com a empresa viram um registro desse relacionamento, essas informações serão registradas mesmo que o contato parte do cliente (por exemplo, reclamações, solicitações). Na Figura 4, é possível observar cada campo do histórico de relacionamento com o cliente.

As ferramentas de CRM podem acessar todas as informações direcionadas aos clientes, e manter todas as informações cadastradas, cada colaborador precisa ter acesso individual ao sistema, pois será possível medir quantas ligações são feitas para os clientes, falar sobre promoções ou apenas para informá-los de que

RC: 85362

Disponível em: https://www.nucleodoconhecimento.com.br/marketing/ferramenta-crm 
chegaram os novos produtos de seu interesse, e ainda registrar as reclamações e problemas técnicos que possam ocorrer após o processo de compra, registrar a quantidade de e-mails enviados ou recebidos pelos clientes, e de acordo com o assunto, informações e prioridade, todas essas informações estão no sistema.

Figura 3: Gráficos de desempenho

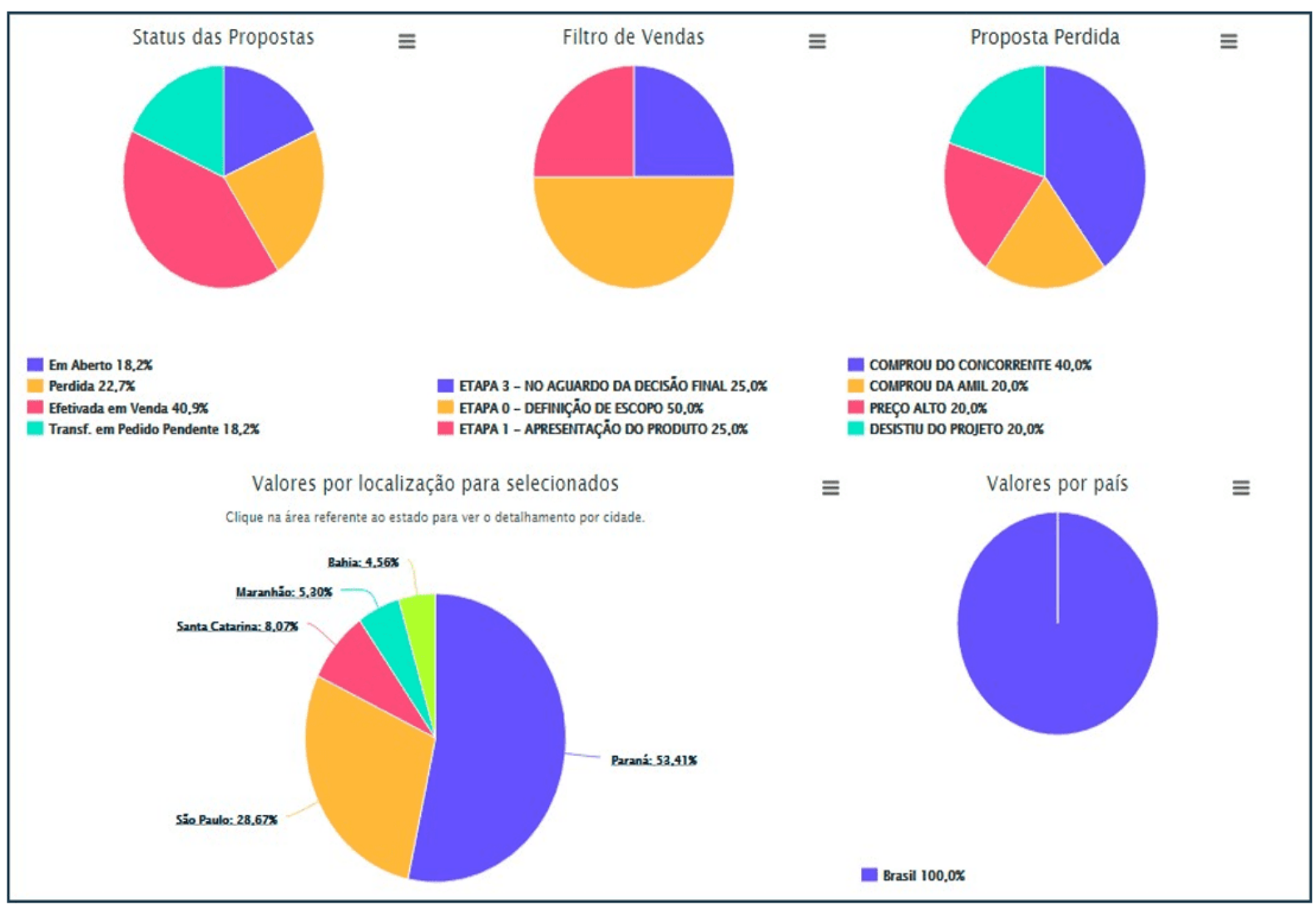

Fonte: CRM Software, 2021.

Nesse sistema é possível cadastrar todos os dados pessoais dos clientes: nome, endereço, telefone, CPF, RG, dados de contato (telefone, celular, e-mail), afiliação, data de nascimento, sexo, estado civil, forma de tratamento, referências comerciais e preferências de pagamento e ainda agendar quando realizarão novos contato com o cliente, há um campo de agenda no sistema que pode ser usado para o registro, como os produtos adquiridos pelo cliente.

$\mathrm{RC}: 85362$

Disponível em: https://www.nucleodoconhecimento.com.br/marketing/ferramenta-crm 
Como mostra a pesquisa, o atendimento é o principal fator na escolha do cliente, e o cliente é a melhor propaganda em qualquer empresa; a propaganda "boca a boca" positiva ou negativa levará ao sucesso ou ao fracasso da organização. As empresas são centradas no cliente, são as pessoas que medem e melhoram o desempenho organizacional.

A adequação para o CRM Analítico para a empresa conseguir analisar os cenários de operação, portanto necessita da criação de relatórios e gráficos, com as informações coletadas pelo CRM Operacional, que auxiliem no acompanhamento de metas de vendas individuais e em equipe, de forma a medir rendimento diário, semanal e mensal, relatórios que classifiquem clientes potenciais, levanta perfil dos clientes, possibilitando a definição do público alvo e ainda relata gráficos para compreender necessidade dos clientes para direcionar ações de vendas no mercado, direcionando ações de marketing.

Mas o processo de implantação do CRM é criterioso; ter diretrizes que norteiam este processo é essencial para compreender quais ações devem ser direcionadas, é comum na implantação do CRM identificar problemas estruturais nos modos de operação e liderança.

O estabelecimento de diretrizes vai direcionar a equipe para a implantação de forma que na identificação dos problemas, fiquem demonstrados os benefícios futuros que o CRM pode trazer à organização.

\section{CONCLUSÕES}

O primeiro objetivo específico busca descrever o conceito e os benefícios do marketing de relacionamento, visão essa apresentada em uma revisão da literatura e, por meio de métodos teóricos, diversos autores comprovaram essa relação. $\mathrm{O}$

RC: 85362

Disponível em: https://www.nucleodoconhecimento.com.br/marketing/ferramenta-crm 
marketing de relacionamento é uma melhoria na manutenção da posição da empresa no mercado.

A análise dos resultados também confirma que a empresa atende com flexibilidade às necessidades do cliente e obtém a fidelidade do cliente como um benefício, que os busca diferenciando-se dos produtos dos concorrentes.

Mostrar capacidade de produção, agilidade na entrega e sustentabilidade da produção do produto, para compreender o marketing de relacionamento e a sua contribuição para a fidelização e retenção de clientes.

O segundo objetivo específico procura identificar as ferramentas que a VAP Informática utiliza para a fidelização e retenção de clientes, diante disso, pode-se dizer que esta pesquisa resolveu com sucesso esse problema, pois a VAP Informática fez o uso da ferramenta CRM para aumentar a fidelização e retenção de clientes.

É óbvio que a empresa também utiliza processos tanto no sistema como nas redes sociais de forma aleatória, portanto, com base nos resultados apresentados, podese considerar que esta pesquisa é uma contribuição ao estimular as empresas a atuarem no sentido de aprimorar os principais pontos, e se espera que estimule pesquisas futuras nesta pesquisa.

O marketing de relacionamento avalia o comportamento da empresa do ponto de vista do cliente para garantir que o comportamento funcione bem e atinja seus objetivos melhor.

Diante dos problemas deste estudo, o marketing de relacionamento deve ser utilizado para possibilitar à empresa oferecer produtos diferenciados aos clientes, pois o produto permanece o mesmo, mais o atendimento e a forma como a empresa recebe o comprador farão com que ele não procure mais outro provedor. A utilização

$\mathrm{RC}: 85362$

Disponível em: https://www.nucleodoconhecimento.com.br/marketing/ferramenta-crm 
desta ferramenta irá melhorar a qualidade do serviço e aumentar a aceitação de novos clientes e torná-los conscientes da sua importância.

O responsável pela organização levará em consideração a promessa ao cliente, mas a comunicação e o relacionamento entre os funcionários são cruciais para construir um bom relacionamento com o cliente, portanto, a equipe precisa estar preparada para prestar um serviço e suporte de qualidade superior, que possa orientar em todos os processos.

\section{REFERÊNCIA}

ALVES, N. et al. O Marketing De Relacionamento Como Ferramenta Para Satisfação E Fidelização De Associados À Cooperativa De Crédito. 2017. Disponível em: http://fapam.ddns.net:8085/admin/monografiasnupe/arquivos/1503201819204020172-ADM-SABRINA_AMARO_e_NATALIA_ALVES.pdf. Acesso em: 13 abr. 2021.

AUGUSTO, M.; JUNIOR, O. Marketing De Relacionamento: A Gestão do relacionamento e suas ferramentas para fidelização de clientes. 2017. Disponível em: http://uniesp.edu.br/sites/_biblioteca/revistas/20170509161603.pdf. Acesso em: 13 abr. 2021.

BARRETO, I.; CRESCITELLI, E. Marketing de relacionamento: como implantar e avaliar os resultados. São Paulo: Pearson Education do Brasil, 2013.

BRETZKE, M.; Marketing de relacionamento e competição em tempo real com CRM (Customer Relationship Management). São Paulo: Atlas, 2000.

BULL, C.; Strategic Issues in Customer Relationship Management (CRM) Implementation. Business Process Management Journal. Bradford v.9, n.5, p.592602, 2003.

$\mathrm{RC}: 85362$

Disponível em: https://www.nucleodoconhecimento.com.br/marketing/ferramenta-crm 
CALADO, S. S.; Ferreira, S. C. R. Análise de documentos: método de recolha e análise de dados. 2004. Disponível em: http://www.educ.fc.ul.pt/docentes/ichagas/mi1/analisedocumentos.pdf Acesso em: 13 abr. 2021.

CAMPOS, V. F. TQC: Controle da qualidade total (no estilo japonês). 9 ed. Nova Lima, MG: Editora Falconi, 2014.

FELLIPINI, D. CRM: Gerando benefícios ao cliente. 2016. Disponível em: < http://www.ecommerce.org.br/o-que-e-crm/>. Acesso em: 13 abri. 2021.

GOMES, M.; KURY, G. A evolução do marketing para o marketing 3.0: o marketing de causa. Intercom. Mossoró - RN. 2013. Disponível em: https://www.marilia.unesp.br/Home/PosGraduacao/Cienciadalnformacao/Dissertacoe s/crivellaro_ff_me_mar.pdf Acesso em 13 de abril de 2021.

KNECHTEL, M. R. Metodologia da pesquisa em educação: uma abordagem teórico-prática dialogada. Curitiba: Intersaberes, 2014.

KOTLER, P.; ARMStRONG, G. Princípios do marketing. 15. ed. São Paulo: Pearson, 2015.

KOTLER, P.; KELLER, K. L.; Administração de marketing. 14. ed. São Paulo: Prentice Hall, 2012.

LAS CASAS, A. L. Marketing de serviços. 4. ed. São Paulo: Atlas, 2006.

LIBÓRIO, D.; TERRA, L. Metodologia científica - São Paulo: Laureate, 2015. P.15. MADRUGA, Roberto.; Guia de implementação de marketing de relacionamento e CRM. São Paulo: Atlas, 2006.

RC: 85362

Disponível em: https://www.nucleodoconhecimento.com.br/marketing/ferramenta-crm 
MINAYO, M. C. S. O desafio do conhecimento: pesquisa qualitativa em saúde. 14. ed. São Paulo: Hucitec, 2014.

NOVELLO, A. Os Benefícios Proporcionados pelo CRM (Customer Relationship Management) nas Pequenas Empresas. 2013. Disponível em: https://faculdadeanglo.com.br/wp-content/uploads/2014/05/Andr\%C3\%A9iaADM.pdf Acesso em: 13 abr. 2021.

SWIFT, R.; CRM: O revolucionário marketing de relacionamento. Rio de Janeiro: Campus, 2014. p.493

TEBOUL, J. Serviços em Cena: o diferencial que agrega valor ao seu negócio. Brasília: IEL/NC, 2008.

VERGARA, S. C.; Projetos e relatórios de pesquisa em administração - 16. Ed. - São Paulo: Atlas, 2016.

VIANNA, I. O. de A. Metodologia do Trabalho Científico. São Paulo: EPU, 2001, $304 p$.

WENNINGKAMP, A. Gerenciamento das relações com o mercado/cliente CRM. Disponível em: https://www.folhavitoria.com.br/economia/blogs/gestaoeresultados/2013/10/31/geren ciamento-das-relacoes-com-o-mercadocliente-crm/. Acesso em: 13 abr 2021.

Enviado: Abril, 2021.

Aprovado: Maio, 2021. 